\title{
Correspondence
}

\section{Calving icebergs indicate a thick layer of temperate ice at the base of Jakobshavn Isbræ, Greenland}

The puzzling fact that Jakobshavn Isbræ, West Greenland, is flowing very fast but without any significant seasonal velocity changes, despite big amounts of surface-derived meltwater entering the ice stream (Echelmeyer and Harrison, 1990), has been explained by a combination of different types of measurements. It is now well established from seismic measurements and radio-echo sounding that Jakobshavn Isbræ flows through a deeply eroded subglacial trench that, even $50 \mathrm{~km}$ inland of the grounding line, extends as far as $1500 \mathrm{~m}$ below sea level (Clarke and Echelmeyer, 1996; Legarsky and Huang, 2006). Temperature measurements in boreholes down to $65 \%$ of the $2500 \mathrm{~m}$ thick ice stream at site B, some $50 \mathrm{~km}$ upstream of the calving front (Fig. 1b; Iken and others, 1993), were used to infer the presence of a substantial layer of temperate ice, the thickness of which was estimated to be at least $300 \mathrm{~m}$ by modeling and matching internal layering structures (Funk and others, 1994; Lüthi and others, 2002). The presence of a thick layer of temperate ice under very high driving stress allows for high ice-deformation rates, which contribute substantially to the observed fast flow velocities. Basal motion, while certainly important, seems to be barely influenced by the seasonal meltwater input (Echelmeyer and Harrison, 1990).
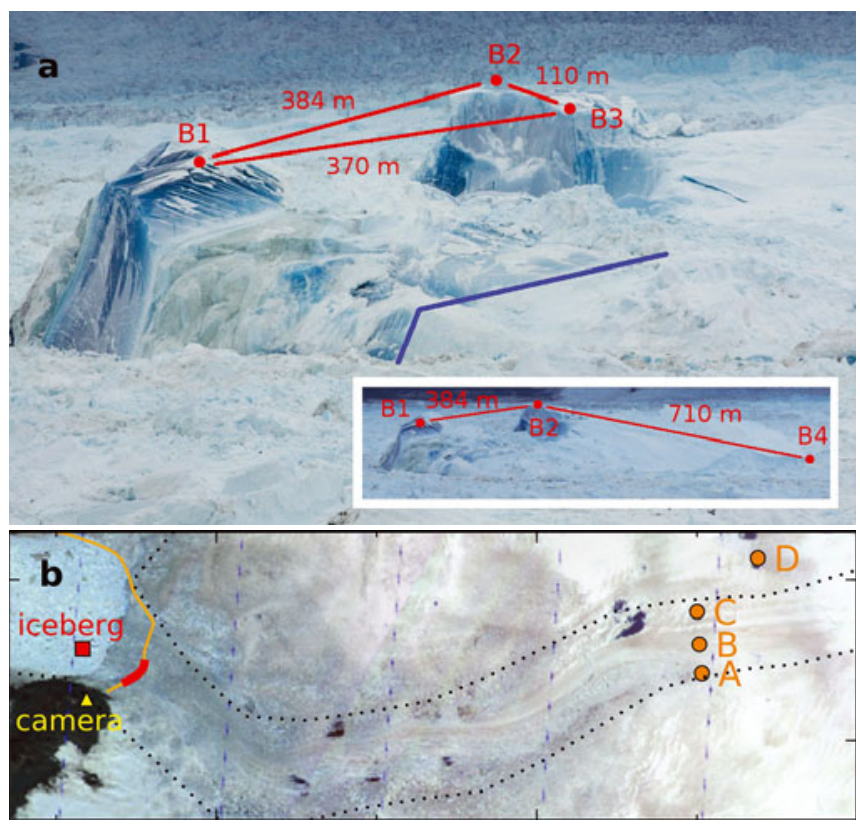

Fig. 1. (a) An iceberg with a thick layer of blue ice, the boundary of which is indicated with a blue line. Natural targets B1-B4 are marked with red points. The inset shows the whole berg, where the line B1-B2 was horizontal and B2-B4 was approximately vertical before calving. Numbers next to red lines indicate measured distances. Elevation above sea level is 116, 147,132 and $29 \mathrm{~m}$ for B1-B4, respectively. (b) Map showing the positions of the iceberg (red square), the glacier terminus 3 days before the calving event (orange curve), the origin of the iceberg (red curve), the camera (yellow triangle) and the drill sites A-D (orange). The ice-stream outlines (dotted) are shown superimposed on a 2005 ASTER satellite image.
Since the 1990s the geometry of the calving front has changed completely (Podlech and Weidick, 2004). The $15 \mathrm{~km}$ long floating tongue, from which kilometer-scale tabular icebergs used to break off, disintegrated in 2002/03. In recent years a smaller floating tongue forms during the winter months and is rapidly removed in spring (Joughin and others, 2008). During most of the summer a substantial part of the calving front is grounded, as is evident from sediments at the bottom of rotated calving icebergs, and the lack of tidal vertical motion (Amundson and others, 2008).

The iceberg shown in Figures 1 and 2 is one of many icebergs that displayed intensely blue ice just after calving. The calving event started on 13 July at 04:47:46 UTC (onset of seismic signal registered at a seismometer next to the camera in Fig. 1b) from a retreated front position (red curve in Fig. 1b). The time-lapse photography shown in Figure 3 (color-enhanced due to poor lighting conditions) shows how the berg rotated backwards during calving, with the basal portion being lifted into the flow direction (towards the left in the image). From the distance scale in Figure 3 (discussed below) we can deduce that the initial vertical extent of the iceberg was $\sim 900 \mathrm{~m}$. After rotating, the iceberg moved at $3.6 \mathrm{~m} \mathrm{~s}^{-1}$ away from the calving front, as determined by tracking features B1-B4. The trace of point B1 (black dots in Fig. 3) shows that the iceberg was rocking with an underdamped harmonic oscillation of $70 \mathrm{~s}$ period, from which an average vertical (initially horizontal) extent of $\sim 600 \mathrm{~m}$ can be calculated (e.g. Sommerfeld, 1994, p. 40, equation 16).

During calving, this iceberg displayed a zone of intensely blue ice (left in Fig. 1, dark in Fig. 3), which was located close to the bottom before rotation, while the rest of the iceberg was whitish in appearance. Whether the blue ice contained liquid water or was frozen could not be determined. The blue color vanished during the next day, presumably by the action of solar radiation.

Positions of four natural targets on the iceberg were measured by triangulation with two theodolites (Leica TM1800

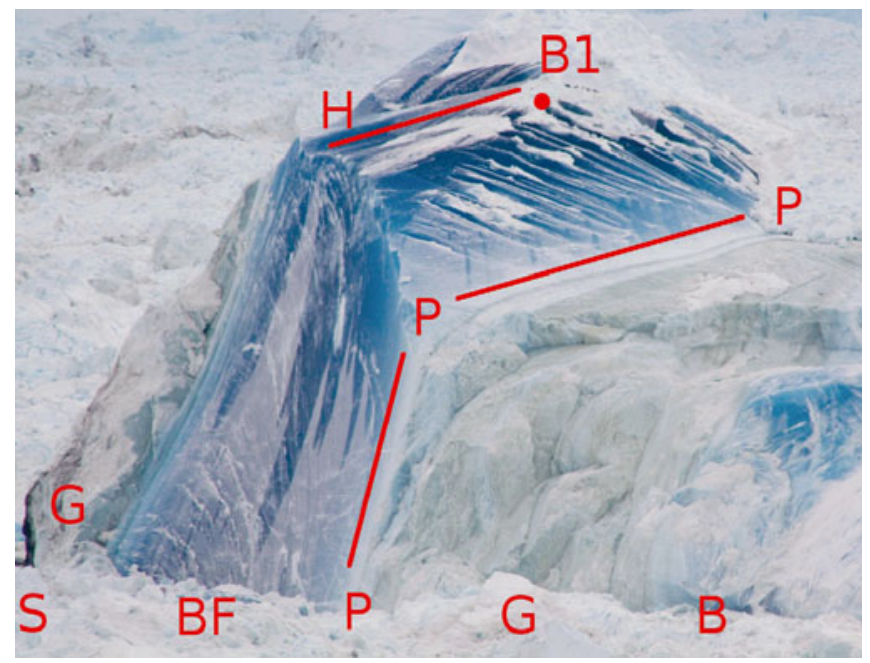

Fig. 2. Close-up view of the lowest part of the iceberg shown in Figure 1. Clearly visible are sediments $(S)$, grayish-green ice $(G)$, blue ice (B), folded blue ice (BF), the fold hinge line $(\mathrm{H})$ and a plane (P) separating blue and green ice. The natural target B1 is marked with a red point. 

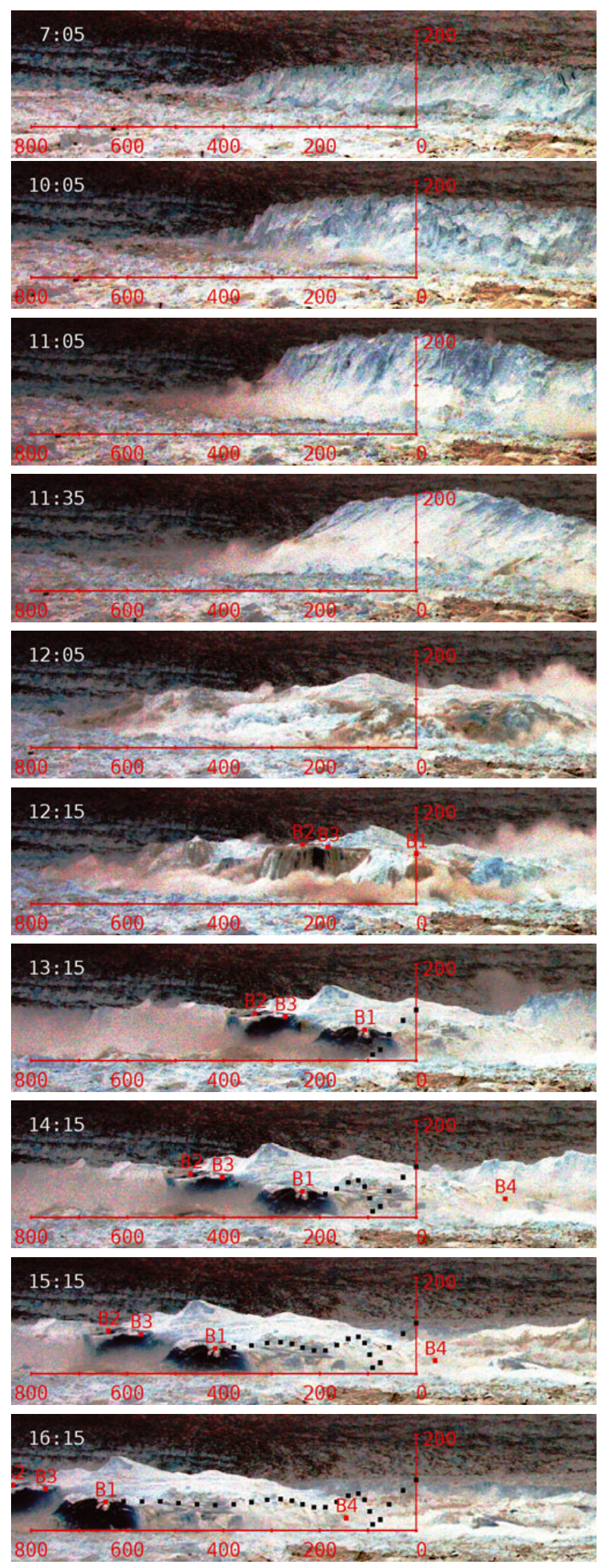

Fig. 3. Time-lapse photography (color enhanced) of the 13 July calving event shown at irregular time intervals. The time in minutes and seconds since onset of seismicity is indicated on the top left. Dark parts of the iceberg correspond to the intensely blue ice in Figure 1. Natural targets B1-B4 are indicated where identifiable. The red scale indicates along-flow distances on the iceberg. The series of black dots mark the positions of B1 every $10 \mathrm{~s}$. and Leica T1600), which were mounted on steel survey stands bolted onto bedrock. The theodolites were $250 \mathrm{~m}$ apart and at a distance of $\sim 4 \mathrm{~km}$ from the iceberg, and measurements took place within $10 \mathrm{~min}$. From repeated measurements of the natural targets B1-B4 (indicated in Fig. 1) we estimate a position accuracy of better than $15 \mathrm{~m}$ in the horizontal, and $3 \mathrm{~m}$ in the vertical. The longest distance measured on the iceberg is $(B 2, B 4)=710 \mathrm{~m}$ in the long axis (inset of Fig. 1a), which was nearly vertical before calving. By identification of B2 and B4 in time-lapse pictures taken during the calving event, the approximate distance scale in Figure 3 was obtained. The distance (B2,B3) is $110 \mathrm{~m}$ and covers roughly the left (initially lower) half of the blue zone. The maximum elevation above sea level of the iceberg is $147 \mathrm{~m}$ at point B2.

From the iceberg dimensions given above, one can estimate a thickness of the blue ice layer of 200-250 m, which is a substantial portion of the calving-front ice thickness of $\sim 900 \mathrm{~m}$. Water depth in the ice-filled fjord downstream of the calving front is uniformly $\sim 800 \mathrm{~m}$ (Holland and others, 2008), but might be less in the grounding-line area where subglacial sediments are likely accumulated. The height of the ice cliff at the calving front after this calving event was between 100 and $130 \mathrm{~m}$, as measured using the method described above. Our natural targets, B1 and B2, were within $100 \mathrm{~m}$ of the bedrock, as can be estimated from Figures 1a and 3, and some sediments are visible at the left in Figure 2 (marked ' $\mathrm{S}$ '). The top $\sim 200 \mathrm{~m}$ broke off during the calving event, as could be determined by analyzing movies and the image sequence (Fig. 3). For the remaining discussion we assume a calving-front thickness of $900 \mathrm{~m}$.

A layering structure is apparent in the blue ice in Figure 2. The layer labeled 'BF' appears to be folded, with the hinge line indicated $\left({ }^{\prime} \mathrm{H}^{\prime}\right)$ in Figure 2. Especially striking is a greengrayish layer $\left({ }^{\prime} \mathrm{G}^{\prime}\right) \sim 50 \mathrm{~m}$ thick in the middle of the blue zone, and separated at the lower end by a straight plane (labeled ' $\mathrm{P}$ ' in Fig. 2). The origin of the green-grayish color is unknown, but it is difficult to imagine an origin from organic sources, as has been observed elsewhere (e.g. Warren and others, 1993). A possible cause of the altered color could be a high dust content, as measured in ice from the late Wisconsin period on the Greenland Icecore Project (GRIP) and Greenland Ice Sheet Project 2 (GISP2) ice cores (e.g. De Angelis and others, 1997). The straight boundary plane (' $P$ ') between greenish and blue ice could be an overthrust fault. Active overthrusting at the transition between Holocene and Wisconsin ice was inferred from erratic ice motion at a drill site, D, $50 \mathrm{~km}$ upstream of the terminus and just outside the ice-stream trunk (Lüthi and others, 2003).

We interpret the blue and white colors of parts of the iceberg as indicators of their thermal state. The white ice (on the right in Figs 1a and 3) likely belongs to the layer of very cold $\left(-22^{\circ} \mathrm{C}\right)$ ice that has been found in all upstream boreholes. We think that the intensely blue color on the left of Figure 1a indicates ice that was at the pressure-melting point, and that contained liquid water. This interpretation, based on appearance, relies on the idea that cold sedimentary ice contains a high density of air bubbles, and that the presence of meltwater alters bubble density and the optical properties of the ice. Observations and measurements of absorption spectra show that clear, bubble-free ice absorbs red light and therefore appears blue, while air bubbles scatter light at all wavelengths and lead to a white opaque appearance (Bohren, 1983; Warren and others, 1993; Warren and Brandt, 2008). 


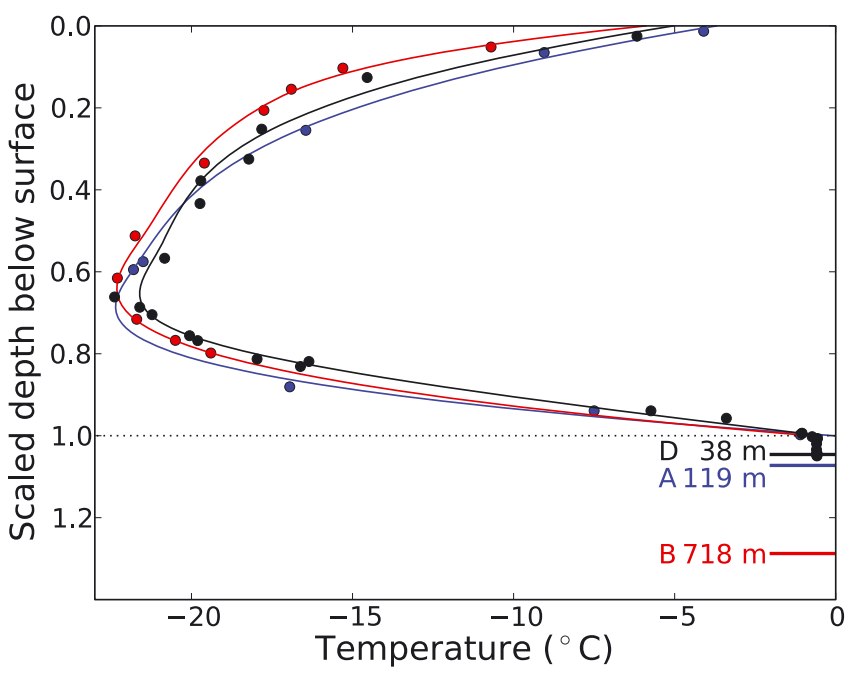

Fig. 4. Temperature profiles from drill sites A, B and D. The vertical scale shows scaled depth below surface such that the transition between cold and temperate ice is at relative depth 1 . Thick horizontal lines indicate the depth of bedrock.

If the above interpretation is correct, one can estimate the thickness of the temperate layer upstream of the grounding line. There, the temperate layer has to be considerably thicker than the 200-250 m deduced from Figure 1a. Ice thickness in the center of the ice stream some $50 \mathrm{~km}$ inland (e.g. at drill site B (Fig. 1b)) is $2500 \mathrm{~m}$ (Clarke and Echelmeyer, 1996) and diminishes to $900 \mathrm{~m}$ or $35 \%$ at the calving front. If vertical strain is evenly distributed throughout the ice column, the assumed $200-250 \mathrm{~m}$ of temperate ice at the terminus would correspond to $600-750 \mathrm{~m}$ at site $\mathrm{B}$, and even more if the temperate ice experiences over-proportional vertical stretching.

An independent estimate of the thickness of the temperate layer in the center of the ice stream can be obtained by comparison of temperature profiles from sites $\mathrm{A}, \mathrm{B}$ and D (from Iken and others, 1993; Lüthi and others, 2002). In these publications a comparison with relative depths, and with internal layering structure, was attempted. Matching the temperature profiles in the cold zone by uniformly stretching the depth scale gives surprisingly good agreement. In Figure 4 the measured temperature profiles are shown on a relative depth scale, such that the transition between cold and temperate ice is at relative depth 1 . Since the ice between the lower end of the cold zone and bedrock has to be temperate, one can estimate the thickness of that layer. For site D this leads to the observed $38 \mathrm{~m}$ of temperate ice, and $720 \mathrm{~m}$ for site $B$.

Both of the above estimates for the thickness of the temperate layer at site B agree. Given the uncertainties involved, this value should be taken with care. If the blue ice observed on many icebergs is indeed at the melting point, a temperate layer of at least $200 \mathrm{~m}$ exists near the terminus, and is likely much thicker upstream.

This short note demonstrates the potential of using rotated icebergs to explore the vertical structure of Jakobshavn Isbræ. Such observations would otherwise be only possible with great logistical effort by drilling through very thick and cold ice.

\section{ACKNOWLEDGEMENTS}

The collaboration with R. Motyka, J. Amundson and J. Brown is gratefully acknowledged. Comments by R. Motyka, R. LeB. Hooke, S. Warren and an anonymous reviewer helped improve the clarity of presentation. Logistics support was provided by VECO Polar Resources. Funding was provided by NASA's Cryospheric Sciences Program (NNG06GB49G), the US National Science Foundation (ARC0531075), the Swiss National Science Foundation (200021-113503/1) and theComer Science and Education Foundation.

Laboratory of Hydraulics,

Martin P. LÜTHI Hydrology and Glaciology (VAW),

ETH Zürich,

CH-8092 Zürich,

Switzerland

E-mail: luethi@vaw.baug.ethz.ch

Institute for the Study of Earth,

Oceans and Space,

University of New Hampshire,

Durham, New Hampshire 03824,

USA

Geophysical Institute,

University of Alaska,

PO Box 757320,

Fairbanks, Alaska 99775-7320,

USA

19 March 2009

Mark FAHNESTOCK

Mark FAHNETOCK

\section{(1)}

\section{REFERENCES}

Amundson, J.M., M. Truffer, M.P. Lüthi, M. Fahnestock, M. West and R.J. Motyka. 2008. Glacier, fjord, and seismic response to recent large calving events, Jakobshavn Isbræ, Greenland. Geophys. Res. Lett., 35(22), L22501. (10.1029/2008GL035281.)

Bohren, C.F. 1983. Colors of snow, frozen waterfalls and icebergs. J. Opt. Soc. Am., 73(12), 1646-1652.

Clarke, T.S. and K. Echelmeyer. 1996. Seismic-reflection evidence for a deep subglacial trough beneath Jakobshavns Isbræ, West Greenland. J. Glaciol., 43(141), 219-232.

De Angelis, M., J.P. Steffensen, M. Legrand, H. Clausen and C. Hammer. 1997. Primary aerosol (sea salt and soil dust) deposited in Greenland ice during the last climatic cycle: comparison with East Antarctic records. J. Geophys. Res., 102(C12), 26,681-26,698.

Echelmeyer, K. and W.D. Harrison. 1990. Jakobshavns Isbræ, West Greenland: seasonal variations in velocity - or lack thereof. J. Glaciol., 36(122), 82-88.

Funk, M., K. Echelmeyer and A. Iken. 1994. Mechanisms of fast flow in Jakobshavns Isbræ, West Greenland: Part II. Modeling of englacial temperatures. J. Glaciol., 40(136), 569-585.

Holland, D.M., R.H. Thomas, B. de Young, M.H. Ribergaard and B. Lyberth. 2008. Acceleration of Jakobshavn Isbræ triggered by warm subsurface ocean waters. Nature Geosci., 1(10), 659-664.

Iken, A., K. Echelmeyer, W. Harrison and M. Funk. 1993. Mechanisms of fast flow in Jakobshavns Isbræ, West Greenland: Part I. Measurements of temperature and water level in deep boreholes. J. Glaciol., 39(131), 15-25.

Joughin, I., S.B. Das, M.A. King, B.E. Smith, I.M. Howat and T. Moon. 2008. Seasonal speedup along the western flank of the Greenland Ice Sheet. Science, 320(5877), 781-783. 
Legarsky, J. and H. Huang. 2006. Correspondence. Detection of main channel thickness from radar data at Jakobshavn Isbræ, Greenland. J. Glaciol., 52(177), 315-317.

Lüthi, M., M. Funk, A. Iken, S. Gogineni and M. Truffer. 2002. Mechanisms of fast flow in Jakobshavn Isbræ, West Greenland. Part III. Measurements of ice deformation, temperature and crossborehole conductivity in boreholes to the bedrock. J. Glaciol., 48(162), 369-385.

Lüthi, A., M. Funk and A. Iken. 2003. Indication of active overthrust faulting along the Holocene-Wisconsin transition in the marginal zone of Jakobshavn Isbræ. J. Geophys. Res., 108(B11), 2543. (10.1029/2003JB002505.)
Podlech, S. and A. Weidick. 2004. Correspondence. A catastrophic break-up of the front of Jakobshavn Isbræ, West Greenland, 2002/03. J. Glaciol., 50(168), 153-154.

Sommerfeld, A. 1994. Vorlesungen ber Theoretische Physik, Band 1: Mechanik. Thun, Verlag Harri Deutsch.

Warren, S.G. and R.E. Brandt. 2008. Optical constants of ice from the ultraviolet to the microwave: a revised compilation. J. Geophys. Res., 113(D14), D14220. (10.1029/2007JD009744.)

Warren, S.G., C.S. Roesler, V.I. Morgan, R.E. Brandt, I.D. Goodwin and I. Allison. 1993. Green icebergs formed by freezing of organic-rich seawater to the base of Antarctic ice shelves. J. Geophys. Res., 98(C4), 6921-6928. 